\title{
Avaliação do Software Educacional e-Sinais no Ensino- Aprendizagem da Língua Portuguesa Escrita e da LIBRAS
}

\author{
Saionara da Silva Araújo1, Daniela G. da Silveira Freitas², Pablo Freire Matos ${ }^{3}$
}

${ }^{1}$ Discente Superior em BSI, ${ }^{2}$ Tradutora e Intérprete de LIBRAS, ${ }^{3}$ Docente de Informática

${ }^{123}$ Instituto Federal de Educação, Ciência e Tecnologia da Bahia (IFBA)

Av. Amazonas, 3150, Zabelê - 45.075-265 - Vitória da Conquista - BA - Brasil

\{narabdo, danielasilveira08, pablofmatos\}@gmail.com

\begin{abstract}
Sinais is a Portuguese word translator software for signs in LIBRAS that looks for assisting deaf students in textual comprehension and facilitating the learning of LIBRAS to listeners, which contributes to a greater autonomy in learning. This paper presents a case study with two groups of students - Group 1, composed of 5 deaf people and Group 2, formed by 11 listeners - in order to evaluate the contribution of the software in the participants' learning. The results show an increase of 29.3\% in Group 1 and $40.6 \%$ in Group 2. The case study showed that, with the software's helping, deaf students and listeners may better understand Portuguese and LIBRAS, respectively, and feel more enthusiastic about learning new words.
\end{abstract}

Resumo. O e-Sinais é um software tradutor de palavras do Português para sinais em LIBRAS que busca auxiliar estudantes surdos na compreensão textual e facilitar o aprendizado de LIBRAS para os ouvintes, o que contribui para uma maior autonomia no aprendizado. Este artigo apresenta um estudo de caso realizado com dois grupos de estudantes - Grupo 1, composto por 5 surdos e o Grupo 2, formado por 11 ouvintes - com o intuito de avaliar a contribuição do software no aprendizado dos participantes. Os resultados mostram um aumento de acerto de 29,3\% no Grupo 1 e de 40,6\% no Grupo 2. $O$ estudo demonstrou que, com o auxílio do e-Sinais, os estudantes surdos e ouvintes conseguem compreender melhor, respectivamente, o Português e a LIBRAS e se sentem mais entusiasmados em aprender novas palavras.

\section{Introdução}

A Língua Brasileira de Sinais (LIBRAS) é utilizada pelos surdos no Brasil e é reconhecida como segunda língua do país. A LIBRAS e o Português são diferentes em níveis de sintaxe por pertencerem às distintas modalidades, respectivamente, visualespacial e oral-auditiva, a tal ponto que estudantes surdos apresentam dificuldades de compreensão e expressão do Português escrito [Quadros, Pizzio e Rezende 2009].

Segundo Basso e Prietch (2016), o desenvolvimento acadêmico e social que se espera de crianças surdas só é possível caso a escola considere suas diferenças linguística e cultural. Este conceito pode ser aplicado a qualquer indivíduo surdo que frequente a escola, em qualquer idade, pois suas necessidades educacionais específicas são baseadas, principalmente, na dificuldade de comunicação por utilizarem uma língua diferente da língua utilizada pela maioria. $\mathrm{Na}$ tentativa de atenuar essas dificuldades, documento oficial no Brasil (2004) assegura como direito de todo estudante surdo ter um intérprete em sala durante o período da aula. 
Os estudantes surdos, desse modo, requerem constante assistência do intérprete para viabilizar sua interação social e sua aprendizagem em livros didáticos escritos em língua portuguesa. Para amenizar as dificuldades encontradas por eles e para facilitar a inclusão plena desses alunos no ambiente escolar, os softwares educativos desenvolvidos para este público surgem como uma opção valiosa que, se bem empregados, podem gerar resultados excelentes. Como sugerem Martins e Matos (2016), os estudantes surdos podem construir seus próprios textos com o uso destes softwares, melhorando tanto as habilidades de escrita quanto de leitura.

Todavia, apenas a inclusão das tecnologias digitais ao processo de ensinoaprendizagem não traz garantia que os professores e alunos terão atitudes diferentes. É preciso que novas propostas de metodologias sejam desenvolvidas para que as tecnologias digitais sejam utilizadas no ambiente educacional de forma eficiente no processo de ensino-aprendizagem [Lima Filho e Castro Filho 2016].

Nesse sentido, este artigo descreve, por meio de um estudo de caso, tanto a avaliação de aprendizagem quanto do software e-Sinais, um tradutor de palavras do Português escrito para sinais em LIBRAS, cujo objetivo é proporcionar aos estudantes surdos a independência nos estudos, além de poder ser utilizado no aprendizado da LIBRAS para pessoas ouvintes. O artigo está estruturado da seguinte forma: Na Seção 2, são resumidos os trabalhos correlatos comparando-os com este trabalho; na Seção 3, são apresentadas as principais características do software educacional e-Sinais; $\mathrm{Na}$ Seção 4, é descrita a realização do estudo de caso com os estudantes surdos e ouvintes; e na Seção 5, são apresentadas a Conclusão e os Trabalhos Futuros.

\section{Trabalhos Correlatos}

Os trabalhos encontrados na literatura têm como objetivo a tradução entre a Língua Portuguesa e a LIBRAS, a fim de auxiliar na comunicação entre surdos e ouvintes [ProDeaf 2017 e HandTalk 2017]; a tradução de LIBRAS para Português [Lima et al. 2012]; a tradução de Português para LIBRAS [Januário, Leite e Koga 2010, Miranda 2013, VLibras 2017, ProDeaf 2017 e HandTalk 2017]; o ensino-aprendizagem do Português para crianças surdas [Santos et al. 2015] ou o ensino-aprendizagem de LIBRAS [Moura et al. 2013 e Sarinho 2017].

$\mathrm{O}$ e-Sinais é um software educacional voltado para o ensino-aprendizagem de Português e de LIBRAS, e diferencia dos demais trabalhos nas seguintes características: adição/alteração de sinais, visualização de imagens associativas e exportação dos sinais para PDF. O ProDeaf (2017) possui o recurso de adição de sinais apenas no aplicativo para smartphones, sendo que o sinal somente é atualizado no programa após aprovação por um responsável pelo aplicativo, diferentemente do e-Sinais que possui uma base de dados independente para cada usuário. O TeachingHand [Santos et al. 2015] é o único que apresenta imagens associativas e não difere do e-Sinais nesta característica. Nenhum trabalho correlato possui o recurso de exportação dos sinais para PDF. O Glossário Letras Libras [Miranda 2013] possui características parecidas com o e-Sinais: trata-se de um dicionário, que traduz palavras para sinais, mostra separação silábica da palavra, explicação do termo, exemplos e variações regionais. O e-Sinais, por sua vez, traduz palavras para sinais no formato GIF e apresenta o nome da palavra na imagem.

\section{3. e-Sinais}

O software e-Sinais [Silva et al. 2016] busca auxiliar estudantes surdos na tradução de 
palavras do Português escrito para sinais em LIBRAS, com o objetivo de viabilizar a aprendizagem de novas palavras, o que possibilita a aprendizagem autônoma e diminui a necessidade de um intérprete ou tradutor humano. Também viabiliza o aprendizado de LIBRAS por estudantes ouvintes. Está disponível sob a licença GNU AGPL e pode ser baixado em https://sourceforge.net/u/e-sinais/profile/.

$\mathrm{O}$ e-Sinais recebe como entrada palavras e retorna ao usuário uma imagem do sinal correspondente em LIBRAS. As palavras digitadas são traduzidas em três etapas: (i) o conjunto é dividido em palavras; (ii) estas palavras são procuradas no banco de dados; e (iii) o sinal retornado pelo banco de dados é mostrado na tela do software. Dois importantes recursos do e-Sinais são: a possibilidade de adição/alteração de sinais e exportação de sinais para PDF. O primeiro recurso permite ao usuário adicionar ou alterar um sinal cadastrado, suprindo a necessidade de adicionar novos sinais inerentes à determinada região. $\mathrm{O}$ segundo facilita o compartilhamento e impressão de sinais para quem não possui o software [Silva et al. 2016].

O software dispunha de cerca de 800 sinais, número pequeno se comparado à quantidade de palavras da Língua Portuguesa. Portanto, o trabalho realizado também teve como objetivo a incorporação de novos sinais ao acervo e o desenvolvimento de nova funcionalidade. As melhorias do software estão descritas nas Seções 3.1 e 3.2.

\subsection{Ampliação do Banco de Dados}

O banco de dados da aplicação é composto por imagens que demonstram os sinais em LIBRAS. Para gerar as imagens, os sinais foram gravados como vídeos curtos e editados para o formato de imagens animadas (GIF). A gravação e a edição dos vídeos foram realizadas por bolsistas selecionados nos Programas Universais da Política de Assistência Estudantil com a temática Atenção às Pessoas com Necessidades Específicas [IFBA 2016]. Além do formato GIF, o e-Sinais também suporta imagens nos formatos JPG e PNG.

Antes de gravar os sinais, foi preciso realizar uma pesquisa a respeito deles, sendo esta a etapa mais demorada, pois foi preciso considerar os seguintes aspectos: (i) o entendimento do sinal pelo surdo, caso o sinal já existisse em outro local (variações regionais); e (ii) a criação de sinais que não foram encontrados nas pesquisas. Como material de apoio nas pesquisas, foram utilizados o dicionário do Instituto Nacional de Educação de Surdos [INES 2008] e o aplicativo ProDeaf (2017). Ao todo foram gravados cerca de 200 sinais em 5 meses.

\subsection{Visualização de Imagem Associativa}

O e-Sinais possui as funcionalidades de tradução, exportação de sinais para arquivos PDF e adição de sinais, o que favorece o crescimento do acervo de sinais, contemplando, por exemplo, sinais conhecidos em determinadas regiões apenas. Além disso, foi desenvolvido o recurso de visualização de imagem associativa, visto que, muitas vezes, apenas um sinal não é suficiente para que o usuário compreenda o significado da palavra pesquisada, especialmente em casos em que o sinal é incomum.

A função deste recurso é buscar no banco de dados e exibir ao usuário a imagem que representa determinado sinal. Para acessá-lo, o usuário deve clicar nos sinais exibidos como resultado da pesquisa e escolher a opção "Mostrar Imagem". A aplicação exibirá em uma janela a imagem associada ao sinal. Na Figura 1, é representada a imagem associativa da palavra "Período". 
VI Congresso Brasileiro de Informática na Educação (CBIE 2017)

Anais do XXIII Workshop de Informática na Escola (WIE 2017)

O banco de dados utilizado foi o HyperSQL (2017) que foi escolhido por ser desenvolvido em Java, ser mais leve que outros bancos e ter a opção de ser executado em memória principal. $\mathrm{O}$ fato de ser desenvolvido em Java facilita a integração com a aplicação que também foi desenvolvida nesta linguagem. Para atender a nova funcionalidade do software, o banco de dados foi alterado, passando a ter mais campos os quais guardam o endereço da imagem e o código único de cada sinal armazenado, além dos campos com nome e endereço do sinal. Na Figura 2, são mostradas as alterações no esquema conceitual do software antes e depois da alteração.

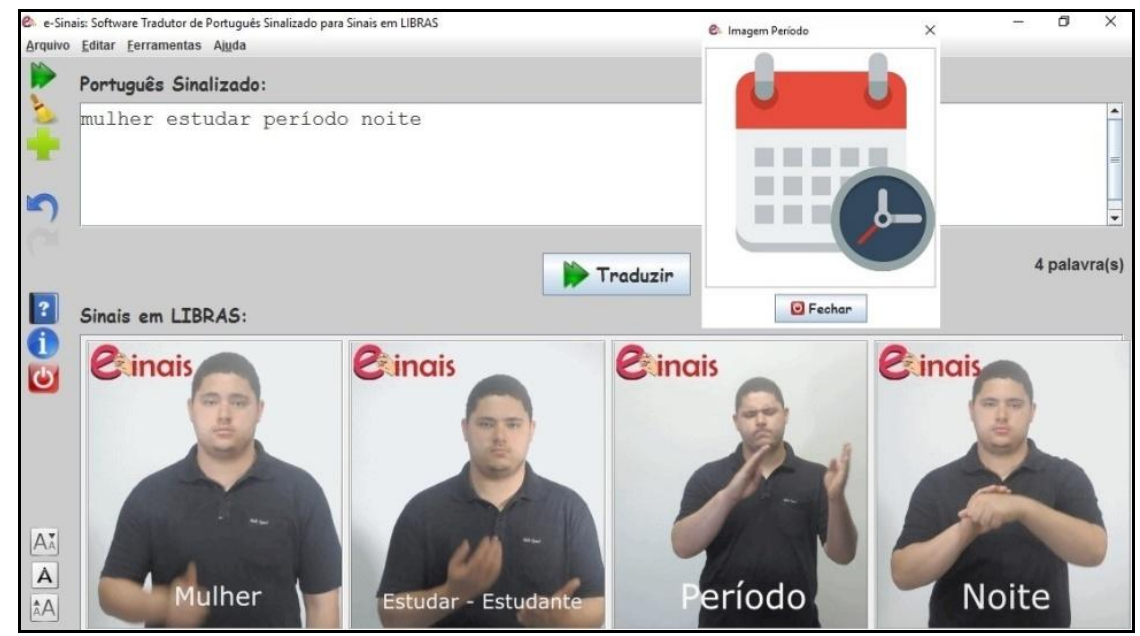

Figura 1. Exibição da imagem associativa. Fonte: Próprio Autor

a)

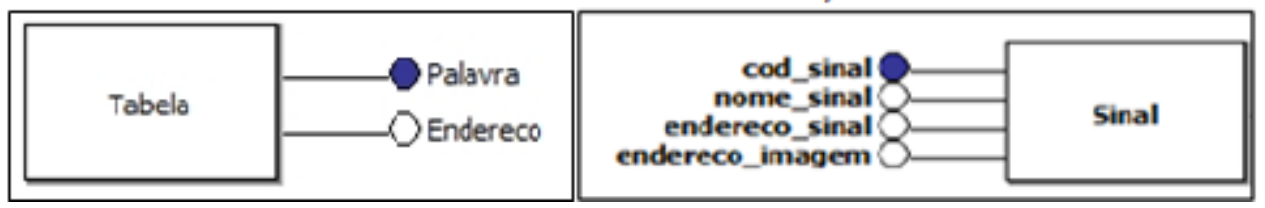

Figura 2. Esquema conceitual do software: a) antes e b) depois da alteração. Fonte: Próprio Autor

\section{Estudo de Caso}

O objetivo deste Estudo de Caso (EC) é avaliar o aprendizado dos estudantes com a utilização do e-Sinais e também avaliar o software em relação às características e o conteúdo do programa.

A amostra do EC foi composta por dois grupos de estudantes do ensino médio: o Grupo 1, formado por 5 estudantes surdos, os quais $20 \%$ eram do sexo feminino e tinham idade entre 17 e 21 anos; e o Grupo 2, composto por 11 estudantes ouvintes, com cerca de $18 \%$ do sexo feminino e com idade entre 16 e 19 anos. O EC foi dividido em etapas, sendo que o Grupo 1 precisou de mais tempo e, por isso, foi realizado em dois dias, enquanto que com o Grupo 2, os mesmos procedimentos ocorreram no espaço de tempo de duas aulas. Na Tabela 1, são resumidas as etapas para os dois grupos de acordo com o tipo de avaliação: de aprendizado ou do software. Para o Grupo 2, durante a Etapa 3, além da explicação sobre o software, também foram realizadas explanações sobre a LIBRAS, suas principais características, as diferenças fundamentais em relação ao Português e ao alfabeto manual. 
A proposta para a avaliação do aprendizado foi indicar a leitura de textos de disciplinas curriculares para, posteriormente, responderem às questões em dois momentos: o Momento 1, sem utilizar o e-Sinais, e o Momento 2, com o auxílio do software. Optou-se por disciplinas das áreas de linguagens e ciências humanas por serem disciplinas que exigem muita leitura e, portanto, retratam as dificuldades dos estudantes surdos com o Português escrito.

Tabela 1. Etapas do Estudo de Caso

\begin{tabular}{|c|c|c|}
\hline Avaliação & Etapa & Procedimentos \\
\hline \multirow{4}{*}{ Aprendizado } & 1 & Explicação do estudo de caso e assinatura dos documentos \\
\hline & 2 & $\begin{array}{l}\text { Leitura e compreensão do texto, e resolução do questionário sem } \\
\text { utilizar o software }\end{array}$ \\
\hline & 3 & Explicação e utilização do software \\
\hline & 4 & $\begin{array}{l}\text { Leitura e compreensão do texto, e resolução do questionário com o } \\
\text { uso do software }\end{array}$ \\
\hline Software & 5 & $\begin{array}{l}\text { Resposta de questionário sobre as características e o conteúdo do } \\
\text { software }\end{array}$ \\
\hline
\end{tabular}

Os textos foram adaptados para os estudantes surdos, pois eles compreendem melhor textos sem alguns elementos do Português, como artigos, preposições, dentre outros. As mudanças propostas residem na ordenação e reestruturação das palavras nas frases. Este processo foi supervisionado por uma intérprete de LIBRAS para que as necessidades específicas dos estudantes surdos com o Português fossem atendidas.

O Grupo 1 deveria ler os textos e responder às questões, divididas em 3 (três) questões objetivas, com peso de $20 \%$ cada e 1 (uma) questão subjetiva, com peso de $40 \%$, para que o participante pudesse escrever uma síntese sobre o que entendeu. Para o Grupo 2, os mesmos textos foram aplicados, e também os mesmos questionários, contudo sem a questão subjetiva. As questões tiveram pesos de 33\% cada. Os textos foram das disciplinas de História e Português do ensino médio.

O primeiro texto utilizado trata sobre a história dos povos pré-colombianos, trabalhado na disciplina de História. Foi um texto curto, de dois parágrafos e, aproximadamente, 200 palavras, que mesmo com as adaptações para que os surdos pudessem ter autonomia no processo de compreensão do texto, trazia palavras pouco comuns ao cotidiano dos participantes. As perguntas objetivas foram do tipo: "No auge do Império Inca, quantas pessoas estavam sob seu domínio?", cuja resposta era facilmente encontrada no texto, sem a necessidade de conhecimento prévio sobre o assunto.

O segundo texto aplicado foi da disciplina de Língua Portuguesa, e contava uma estória sobre uma viagem de 3 (três) personagens: um caboclo, um padre e um estudante. Este texto foi um maior que o primeiro (400 palavras) e também com mais detalhes, como diálogos entre os personagens e descrições de alguns objetos do cenário. Assim como o primeiro texto, para ser aplicado aos participantes surdos, o texto passou por adaptações, que de acordo com relatos dos participantes, não foi tão adaptado quanto o primeiro. As perguntas tiveram o mesmo peso que o texto anterior, e foram questões objetivas, em que algumas possuíam mais de uma opção correta, e outras apenas uma.

Os questionários para avaliação de qualidade do e-Sinais também foram aplicados aos dois grupos. Esses questionários foram elaborados com base na norma de 
VI Congresso Brasileiro de Informática na Educação (CBIE 2017)

Anais do XXIII Workshop de Informática na Escola (WIE 2017)

qualidade de software, especificamente a NBR ISO/IEC 9126-1 [Júnior, Aguiar e Tavares 2016].

\subsection{Avaliação do Aprendizado}

Após a aplicação dos textos e questionários, a pontuação dos participantes foi avaliada de forma a mensurar o quanto o uso do software auxiliou na compreensão dos textos pelos estudantes surdos (Grupo 1), e no aprendizado de novos sinais pelos estudantes ouvintes (Grupo 2). A partir da soma de pontos obtidos nas questões dos questionários, contabilizou-se a média dos participantes. Como se pode observar na Figura 3, a média de acertos no Momento 2 aumentou em todos os participantes, exceto o Participante 5 do Grupo 2, pois o mesmo não se sentiu bem e precisou deixar o estudo de caso.

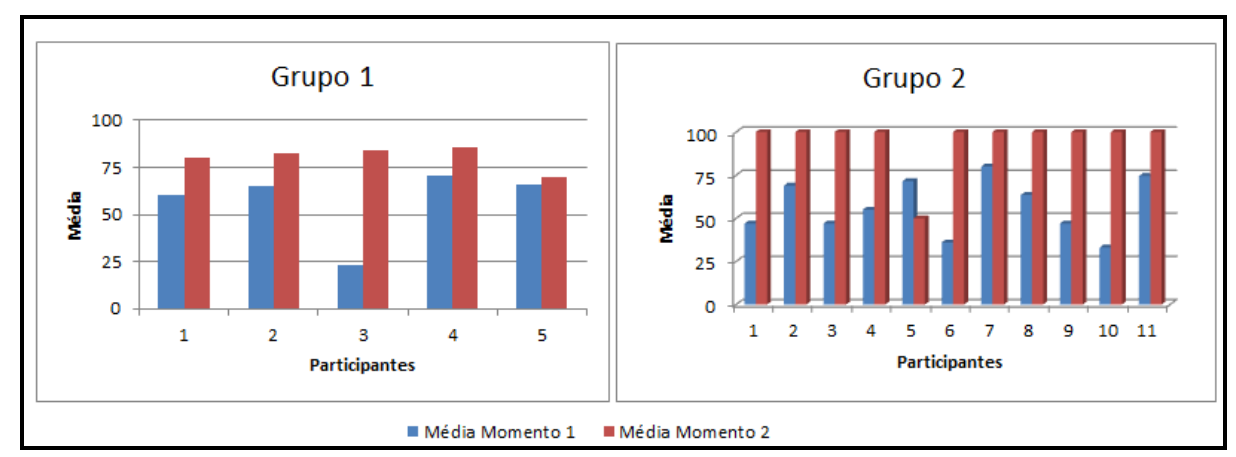

Figura 3. Média dos participantes nos dois momentos. Fonte: Próprio Autor

Também foi calculada a média aritmética dos grupos obtida após a aplicação dos dois textos (Figura 4). As médias aumentaram entre um momento e outro, passando de 56,9 para 80,5 pontos, com aumento de $29,3 \%$ no Grupo 1, e de 56,68 para 95,45 pontos, com aumento de 40,6\% no Grupo 2 .

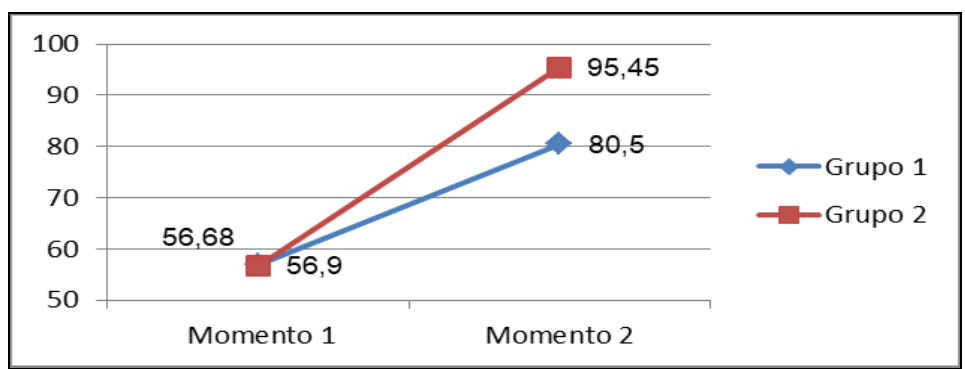

Figura 4. Gráfico das médias dos grupos. Fonte: Próprio Autor

As razões no aumento das médias para o Grupo 1 ocorreram, principalmente, em relação às questões de síntese, pois $80 \%$ dos participantes surdos declararam que, assim como acontece na sala de aula, iriam copiar palavras do texto para que o resumo fosse construído. Percebe-se com isso que, quando questionados sobre a compreensão de determinado texto, a ação imediata dos estudantes surdos é apenas fazer cópias de palavras soltas. Contudo, ainda assim, observou-se que a síntese dos textos de um momento para outro melhorou. Enquanto no Momento 1, houve várias cópias de palavras soltas; no Momento 2, por outro lado, as palavras já não eram copiadas aleatoriamente, e sim em um contexto de determinadas frases do texto.

Sobre a diferença de médias do Grupo 2, percebe-se que o aumento de acerto no Momento 2 ocorreu, pois os participantes podiam pesquisar os sinais referentes às 
VI Congresso Brasileiro de Informática na Educação (CBIE 2017)

Anais do XXIII Workshop de Informática na Escola (WIE 2017)

principais palavras do texto, e podiam responder ao questionário usando o software, enquanto que, sem utilizar o software, os participantes tentaram identificar os sinais que se adequavam às perguntas apenas com base nas características básicas da LIBRAS, explicadas no início do estudo de caso.

\subsection{Teste de Hipótese}

Partiu-se da hipótese segundo a qual a média dos grupos, no Momento 2, é igual ou superior à média no Momento 1 , e foi testada através do teste estatístico. Para validar os dados, foram aplicados os testes de Shapiro-Wilk [Portal Action 2017], para inferir sobre o tipo de distribuição dos dados, o teste $\mathrm{F}$ de variâncias para verificar qual o melhor parâmetro para o teste T-Student [Fonseca e Martins 1996] e, por fim, o teste TStudent para variâncias diferentes. Na Tabela 2, são mostrados os resultados do teste TStudent para os dados dos dois grupos.

Tabela 2. Teste T para duas amostras com variâncias diferentes

\begin{tabular}{|c|c|c|c|c|}
\hline & \multicolumn{2}{|c|}{ Grupo 1} & \multicolumn{2}{|c|}{ Grupo 2} \\
\hline & $\begin{array}{c}\text { Sem o } \\
\text { software }\end{array}$ & $\begin{array}{c}\text { Com o } \\
\text { software }\end{array}$ & $\begin{array}{c}\text { Sem o } \\
\text { software }\end{array}$ & $\begin{array}{c}\text { Com o } \\
\text { software }\end{array}$ \\
\hline Média & 56,9 & 80,5 & 56,68 & 95,45 \\
\hline Variância & 374,3 & 39,25 & 255,16 & 227,27 \\
\hline Observações & 5 & 5 & 11 & 11 \\
\hline Hipótese da diferença de média & \multicolumn{2}{|c|}{0} & \multicolumn{2}{|c|}{0} \\
\hline Graus de liberdade & \multicolumn{2}{|c|}{4} & \multicolumn{2}{|c|}{10} \\
\hline Estatística T encontrada & $-2,59$ & & $-5,85$ & \\
\hline $\mathrm{P}(\mathrm{T}<=\mathrm{t})$ uni-caudal & 0,024 & & $4,99 \mathrm{E}-06$ & \\
\hline t crítico uni-caudal & 2,01 & & 1,72 & \\
\hline
\end{tabular}

Observa-se que os valores da variável T, -2,59 para o Grupo 1 e $-5,85$ para o Grupo 2 é menor que os valores da variável T crítico, respectivamente, 2,01 e 1,72. Pode-se constatar, então, que a hipótese nula levantada no trabalho deve ser rejeitada, a saber: a média obtida pelos participantes com o uso do software é igual ou inferior à média obtida sem o auxílio do software. Com os resultados dos testes, foram gerados gráficos com os intervalos de confiança relativos às médias dos grupos definidos em 95\% (Figura 5).

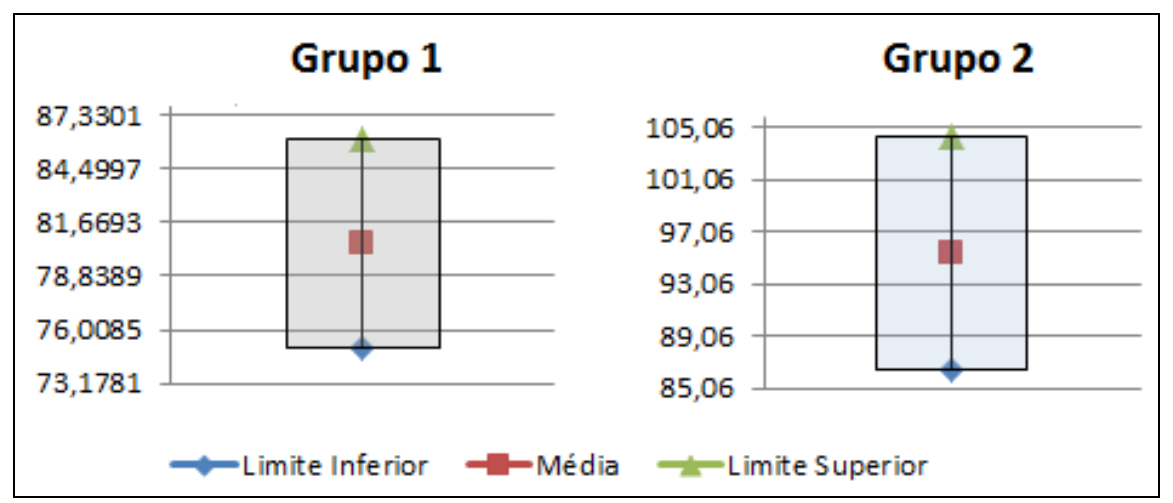

Figura 5. Intervalo de confiança para as médias dos Grupos. Fonte: Próprio Autor

Com base nestes gráficos, pode-se afirmar, com 5\% de erro, que os resultados dos testes com as amostras são representativos em relação à população, o que significa que, em 95\% dos casos, com os mesmos parâmetros demonstrados neste trabalho, o resultado das médias será muito próximo ao encontrado neste estudo de caso. 


\subsection{Avaliação do Software}

Na Figura 6, são demonstradas as respostas do Grupo 1 sobre a relação deles com o estudo do Português escrito. Quando perguntados sobre a dificuldade em estudar Português sem o software e sobre estudar fora do horário de aulas ou monitorias, $60 \%$ indicaram que sentiram mais dificuldade sem o uso do e-Sinais (Figura 6-a) e que não tem o hábito de estudar por conta própria, fora das aulas ou monitorias (Figura 6-b), o que demonstra dependência de auxílio para o estudo de disciplinas que exigem muita leitura. Ademais, $100 \%$ declararam que o e-Sinais mantém sua atenção, que usaria novamente a ferramenta e que a indicaria a outras pessoas.

Ainda para os participantes do Grupo 1,60\% dos sinais são claros e de fácil entendimento, é simples aprender a utilizar o software e o uso da ferramenta os motivou a estudar Português. Sobre o conteúdo abordado pelo software, $80 \%$ afirmou que o conteúdo é relevante.

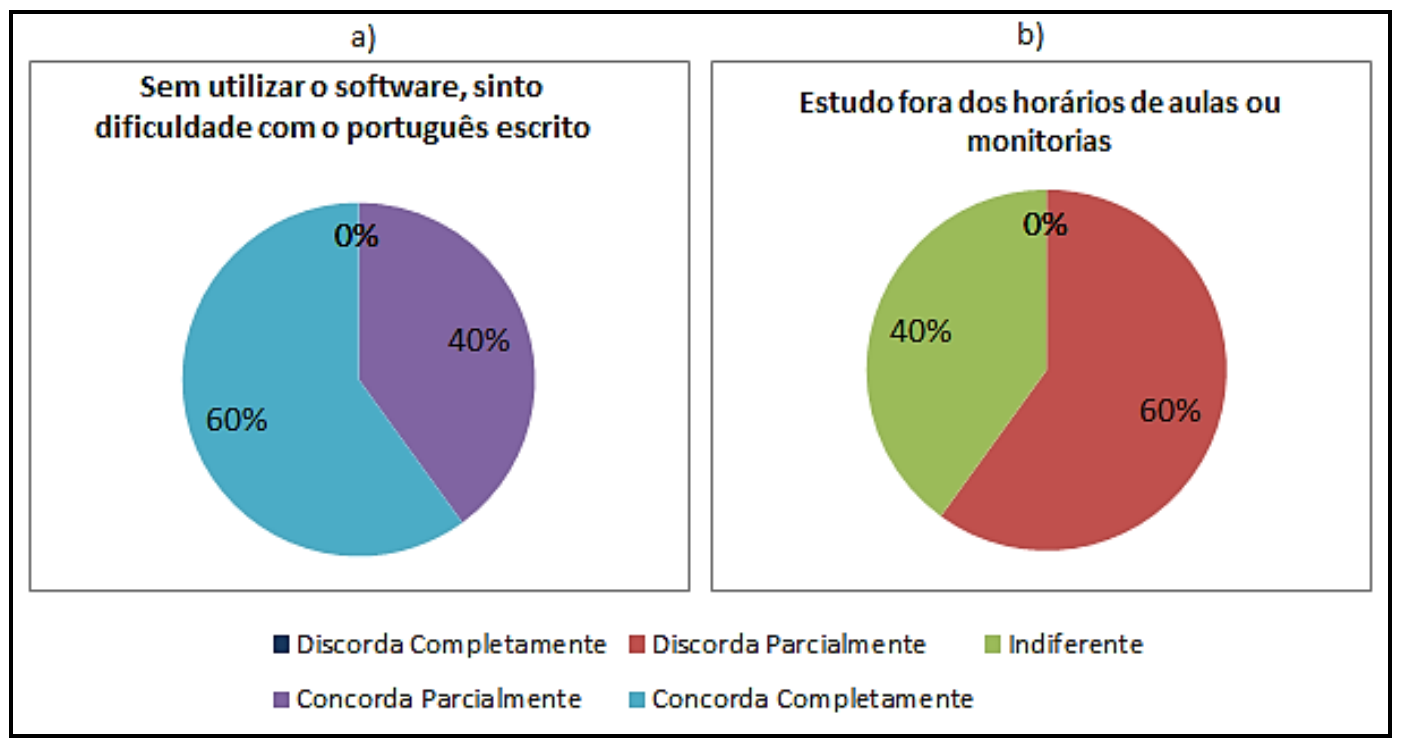

Figura 6. Avaliação do Grupo 1 sobre estudo de Português. Fonte: Próprio autor

O Grupo 2 ao responder sobre a relevância do conteúdo abordado afirmou concordar em $40 \%$ com a importância do conteúdo que o software aborda. A maioria dos participantes, $60 \%$, considerou que o software tem tempo de resposta satisfatório e que é fácil aprender a usá-lo. Porém, 60\% afirmou que o software não prendeu sua atenção. Contudo, $80 \%$ afirmou que usaria novamente a ferramenta e $60 \%$ a indicaria.

Sobre o hábito de estudar LIBRAS por iniciativa própria e sobre o software causar motivação para tal atitude, 30\% afirmou não estudar LIBRAS (Figura 7-a) e não se sente motivado a realizar esta atividade com o software (Figura 7-b). Contudo, 90\% concordou que o software diminui as dificuldades com a LIBRAS (Figura 7-c).

De acordo com a avaliação realizada, o software conta com uma interface amigável e foi avaliado positivamente pelos participantes, segundo $60 \%$ dos estudantes surdos e $50 \%$ dos ouvintes. Sobre a usabilidade, o software também foi bem avaliado, pois $80 \%$ e $60 \%$ dos participantes, respectivamente, do Grupo 1 e do Grupo 2 afirmaram estar satisfeitos com o tempo de resposta, a facilidade de navegação e a exibição dos sinais. 
VI Congresso Brasileiro de Informática na Educação (CBIE 2017)

Anais do XXIII Workshop de Informática na Escola (WIE 2017)

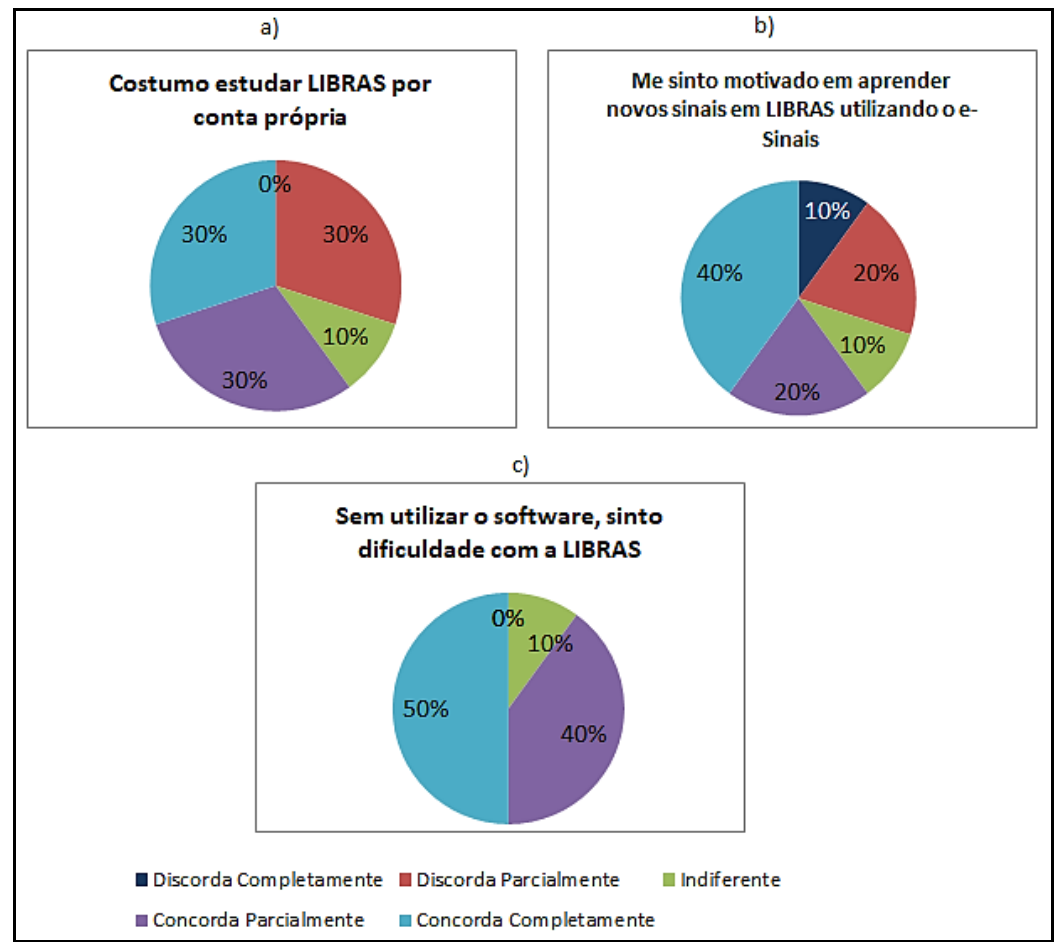

Figura 7. Avaliação do Grupo 2 sobre o estudo da LIBRAS. Fonte: Próprio autor

\section{Conclusão}

Como mostraram os resultados do estudo de caso em um intervalo de confiança de $95 \%$ (Figura 5), o crescimento das médias dos grupos, de aproximadamente $29 \%$ para o Grupo 1 e 40,6\% para o Grupo 2, permite afirmar que o software serve como auxílio para os estudos dos surdos, proporcionando-lhes mais independência para momentos em que não podem contar com intérprete, além de poder ser utilizado por pessoas ouvintes no aprendizado da LIBRAS, buscando melhorar a comunicação entre surdos e ouvintes em qualquer ambiente onde se estabeleça a interação social.

Com os resultados discutidos neste artigo, é possível perceber que o grupo de estudantes surdos se identificou melhor com o software, sendo este o público-alvo principal, mas também os estudantes ouvintes apresentaram, na maioria das vezes, simpatia ao uso do e-Sinais. O aumento das médias dos grupos, quando comparado em relação ao uso ou não do programa, permite concluir que o e-Sinais auxilia os estudantes surdos na compreensão do Português, dando maior autonomia na vida acadêmica, e que pode ser utilizado como ferramenta para o aprendizado da LIBRAS para pessoas ouvintes.

Como trabalhos futuros, pretende-se desenvolver funcionalidades para que o programa possa sugerir sinônimos, palavras que possuem o mesmo significado, palavras polissêmicas, que são as que possuem mais de um significado, a exemplo da palavra manga; e antônimos, palavras com significado oposto, para as palavras pesquisadas. Essas funcionalidades permitirão ao usuário a seleção do sinal mais adequado ao contexto do que está sendo pesquisado. A expansão do banco de dados também deve ser considerada como um trabalho a ser continuado. Além disso, outra sugestão é que o eSinais tenha suporte a gravação e edição de sinais internamente, para que este processo seja parte dos recursos do software, facilitando ainda mais a adição de novos sinais. 
VI Congresso Brasileiro de Informática na Educação (CBIE 2017)

Anais do XXIII Workshop de Informática na Escola (WIE 2017)

\section{Agradecimentos}

Agradecemos o apoio do NAPNEE (Núcleo de Atendimento à Pessoa com Necessidades Educacionais Específicas) do IFBA Campus Vitória da Conquista/BA, e a participação dos estudantes (surdos e ouvintes) e da intérprete que contribuíram no desenvolvimento do projeto e na realização do estudo de caso. Em especial, agradecemos a professora de português do IFBA, Josilene Domingues Santos Pereira, pela revisão final do artigo.

\section{Material Complementar}

Os questionários completos da avaliação do aprendizado e do software podem ser visualizados no endereço https://goo.gl/ngB9uE.

\section{Referências}

Basso, G. e Prietch, S. (2016) Acessibilidade em Websites de Instituições Escolares com foco no Atendimento aos Usuários Surdos. In: XXII WIE, pages 835-844.

Brasil. Constituição. (2004) Decreto $n^{\circ} 5296$, de 2 de outubro de 2004. Brasília, DF.

Fonseca, J. S. e Martins, G. A. (1996) Curso de estatística. $6^{a}$ ed. São Paulo: Atlas.

Handtalk. (2017) "Tradutor de Sites", https://handtalk.me/sites.

HyperSQL. (2017) "HSQLDB - 100\% Java Database", http://hsqldb.org/.

IFBA. (2016) "Edital No 005, 25 de maio de 2016: Política de Assistência Estudantil Programas Universais", https://goo.gl/kfXiod.

INES. (2008) "Dicionário da Língua Brasileira de Sinais - LIBRAS", http://www.acessibilidadebrasil.org.br/libras/.

Januário, G. C., Leite, L. A. F. e Koga, M. L. (2010) Poli-Libras: Um tradutor de português para libras. Trabalho de Conclusão de Curso. USP, São Paulo.

Júnior, O. B., Aguiar, Y. e Tavares, T. (2016). Abordagens para Avaliação de Softwares Educativos e sua Coerência com os Modelos de Qualidade de Software. In: XXVI SBIE, pages 270-279.

Lima Filho, C. B. e Castro Filho, J. A. (2016) Análise de uma Proposta Metodológica para Uso das Tecnologias Digitais no Ambiente Escolar. In: XXII WIE, pages 427-436.

Lima, M. A. S. et al. (2012) LIBRAS translator via web for mobile devices. In: XII EATIS, pages 399-402.

Martins, L. M. N. e Matos, L. H. A. (2016). Tecnologia e Educação de Surdos: Possibilidades de Intervenção. Nuances: estudos sobre Educação, 26(2), 188-206.

Miranda, R. D. (2013) Software Livre Glossário Letras Libras. Trabalho de Conclusão de Curso. UFSC, Florianópolis.

Moura, G. et al. (2013) Luz, Câmera, Libras!: How a Mobile Game Can Improve the Learning of Sign Languages. In: Marcus, A. (Ed.), DUXU/HCII, pages 266-275.

Portal Action. (2017) "Teste de Shapiro-Wilk", http://www.portalaction.com.br/inferencia/64-teste-de-shapiro-wilk.

Prodeaf. (2017) "Soluções ProDeaf", http://prodeaf.net/pt-br/Solucoes.

Quadros, R. M., Pizzio, A. L. e Rezende, P. L. F. (2009) Lingua Brasileira de Sinais I. Florianópolis: UFSC.

Santos, P. V. et al. (2015) Teaching Hand: Uma Plataforma Educacional para o Ensino da Língua Portuguesa para Crianças Surdas. In: IV CBIE - X LACLO, pages 441-446.

Sarinho, V. T. (2017) LibrasZap: An Instant Messaging Game for Knowledge Assessment in Brazilian Sign Language. RBIE.

Silva, I. Q. et al. (2016) e-Sinais: Software Tradutor de Português Sinalizado para Sinais em LIBRAS. In: III EnCompIF, pages 716-719. CSBC.

VLibras. (2017) "Tradução de Português para LIBRAS", http://www.vlibras.gov.br/. 